\title{
The triple oxygen isotope composition of phytoliths, a proxy of relative humidity: impact of the triple oxygen isotope composition of soil water and vegetation type
}

\author{
ANNE ALEXANDRE ${ }^{1}$, CLÉMENT OUTREQUIN ${ }^{2}$,
} CHRISTINE VALLET-COULOMB ${ }^{3}$, CHRISTOPHE PEUGEOT $^{4}$, SIMON AFOUDA $^{5}$, MARTINE COUAPEL 6 , AMAELLE LANDAIS ${ }^{7}$, JEAN-CHARLES MAZUR ${ }^{1}$, CORINNE SONZOGNI ${ }^{8}$, THEODORE OUANI ${ }^{6}$ AND MAXIME WUBDA ${ }^{6}$

${ }^{1} \mathrm{CNRS}$, CEREGE

${ }^{2}$ Aix-Marseille University, CEREGE

${ }^{3}$ Aix-Marseille Université, CEREGE

${ }^{4}$ IRD, Hydrosciences Montpellier

${ }^{5}$ IRD

${ }^{6}$ IRD, CEREGE

${ }^{7}$ LSCE - Institut Pierre Simon Laplace

${ }^{8}$ Aix Marseille Univ, CNRS, IRD, INRAE, Coll France, CEREGE

Presenting Author: alexandre@cerege.fr

Continental atmospheric humidity is a key climate parameter poorly captured by global climate models. Model-data comparison approaches applicable beyond the instrumental period are essential to progress on this issue but face a lack of relative humidity records. This study is part of the HUMI-17 project that assesses the robustness of the ${ }^{17} \mathrm{O}$-excess of phytoliths as a proxy of past changes in atmospheric relative humidity. Here, the impact of the triple oxygen isotope composition of soil water and vegetation type on the triple oxygen isotope composition of phytoliths is examined. We additionally assess which relative humidity (annual or seasonal? averaged over the plant growing period or over the growing period and the beginning of senescence?) is registered by the ${ }^{17} \mathrm{O}$-excess of phytoliths. At last, we examine how tree phytoliths contribute to the relative humidity proxy. For that purpose, rainwater, soil cores, grasses and trees were sampled at the AMMA-CATCH natural observatory in Benin (West Africa) where dry forest and savannas develop under a tropical humid climate. The site is equipped with a meteorological station. The triple oxygen isotope compositions of rainwater, soil water and plant water were analyzed by isotope ratio mass spectrometry (IRMS) and cavity ring-down spectrometry. Phytoliths were analyzed by laser-fluorination-IRMS. For robust comparisons between triple oxygen isotope compositions acquired by different analytical techniques, on different phases, inter-laboratory comparisons have been carried out. Overall, the results bring us closer to an accurate proxy of changes in relative humidity. 